\title{
Nonlinear Modeling of Transmission Performance for Permanent Magnet Eddy Current Coupler
}

\author{
Xiaowei Yang $(\mathbb{D}$, Yongguang Liu, and Liang Wang \\ School of Automation Science and Electrical Engineering, Beihang University, Beijing 100191, China \\ Correspondence should be addressed to Xiaowei Yang; 1_yangxiaowei@163.com
}

Received 7 October 2018; Revised 25 February 2019; Accepted 18 April 2019; Published 2 May 2019

Academic Editor: Ruben Specogna

Copyright (C) 2019 Xiaowei Yang et al. This is an open access article distributed under the Creative Commons Attribution License, which permits unrestricted use, distribution, and reproduction in any medium, provided the original work is properly cited.

\begin{abstract}
Establishing the analytical model for accurately predicting the transmitted torque of the permanent magnet eddy current coupler (PMEC) with double conductor rotors is very important to study the nonlinear transmission performance of the PMEC. In this paper, based on magnetic equivalent circuit (MEC) approaches, considering the effects of permanent magnet (PM) end leakage, side leakage, and back iron saturation, the 3D magnetic field model of the PMEC is established. Based on the magnetic field model, combined with Faraday's law and Ampere's law, the 3D nonlinear model of the PMEC is established. The proposed model adopts the Jenei method to describe the inductance limited eddy current field. The theoretical data, 3D finite element method (FEM) data, and experimental data are compared. The research shows that the predicted value of the analytical model matches well with the torque obtained by 3D FEM and experiments in the range of 0-100\% slip, with an error less than $5.3 \%$ observed. Finally, the influence of structural parameters on the transmission performance of the PMEC is studied by using the proposed model.
\end{abstract}

\section{Introduction}

Large-scale rotating equipment is the important power equipment in many areas, such as electric industry, iron \& steel industry, petrochemical industry, transportation, and so on. The power system is connected by coupling to transfer the power. The traditional coupling is very strict in alignment; otherwise it will cause serious vibration, even major accidents such as equipment damage $[1,2]$. In order to solve the problem of alignment, researchers have successfully explored a nonphysical contact transmission technology. It is magnetically coupled technology [3-6]. The the permanent magnet eddy current coupler (PMEC) usually consists of permanent magnets (PMs) rotor and conductor rotor, as shown in Figure 1. The PMs rotor includes PMs and back iron, and the conductor rotor includes copper and back iron $[7,8]$. The research of electromagnetic field is the core and foundation of the PMEC. At present, the research methods mainly include numerical methods and analytical methods [9-12]. The finite element method (FEM) is a typical numerical method $[13,14]$. $\mathrm{Li} Z$ et al. study the magnetic field, eddy current, and torque of the PMEC by the 3D FEM. Compared with experiment, the validity of the 3D FEM was verified [3]. Hyeon-JaeShin et al. take the PMEC as the research object. The influence of structure parameters on the transmission of the PMEC is studied by 3D FEM. The accuracy of the FEM results was verified by experiments [4]. Dong $\mathrm{K}$ et al. establish a 1/6 3D FEM model of the PMEC and study the efficiency of the PMEC [15]. The FEM can give accurate prediction results in the study of electromagnetics. But the FEM has long calculation times and is less flexible; therefore, FEM is not applicable in the initial design stage of electromagnetic fields [16-19]. The magnetic equivalent circuit (MEC) method is a common analytical method. The MEC simplifies the geometry or material nonlinearity and can quickly determine the influence of key design parameters [20-24]. Mohammadi $S$ et al. use the MEC to study the performance of the PMEC. Compared with experiment and FEM, the validity of the model was verified under $8 \%$ slip [25-27]. Wang J et al. study the transmission performance of the PMEC by the MEC, and accurate prediction torque was obtained at $10 \%$ slip $[28,29]$. Based on MEC, the conductivity of copper is regarded as a constant value, and the inductance characteristics of copper are neglected. Current studies show that results according to this model are not always accurate. Further, when slip is 


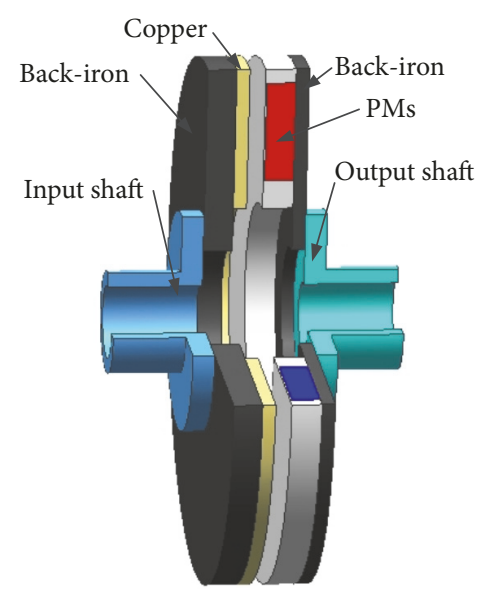

FIGURE 1: Structural diagram of the PMEC.

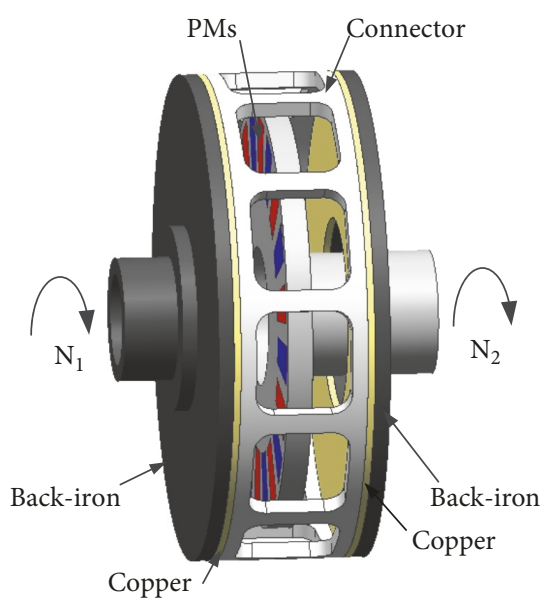

FIgURE 2: Structural diagram of the PMEC with double conductor rotor.

higher than $10 \%$ the error model is unacceptable, such that present studies are limited to less than $10 \%$ slip [25-31]. In literature [32], according to the slip, the Russell-Norsworthy factor is continuously revised, and the theoretical value is basically consistent with the FEM value within $100 \%$ slip. Literature [33-35] adopts Maxwell's equations, and Zheng D et al. adopt the accurate subdomain method [36-38], where torque characteristics are studied under $100 \%$ slip. Good results were obtained, especially at low slip speed. In addition, literature $[39,40]$ regarding the back iron with infinite or a set permeability has shown that the saturation effect is neglected in the back iron.

In this paper, the PMEC with double conductor rotor is taken as the research object. The PMEC is shown in Figure 2. Compared with Figure 1, it consists of a set of the PMs rotor and two sets of the conductor rotors. Combining MEC, Faraday's, and Ampere's laws, a 3D magnetic field model is built that includes edge effect and iron saturation effect. The Jenei method is used to describe the inductance characteristics of copper, and the dynamic conductivity of copper rotor is proposed. The nonlinear torque model of

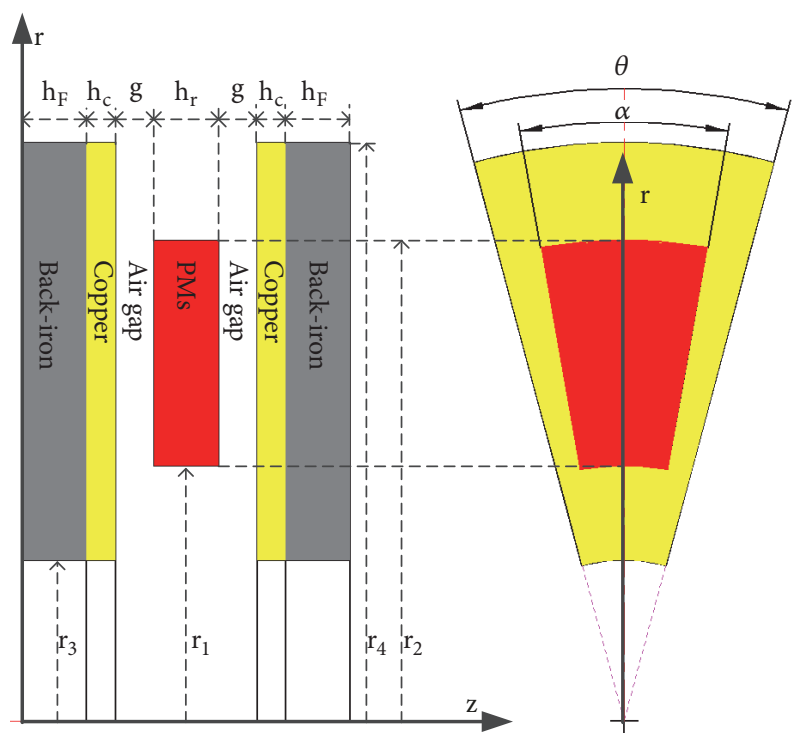

FIgUre 3: The graph of the PMEC on r-z and r- $\theta$ planar.

the PMEC is established, which can predict the transmission performance of the PMEC from 0-100\% slip. Compared with the 3D FEM and experiment, the validity of the proposed model is verified, and the influence of sensitive parameters on the transmission performance of the PMEC is researched.

\section{Magnetic Field Modeling}

2.1. Problem Description and Idealization. The distribution of the PMEC on the $r-z$ and $r-\theta$ planes is shown in Figure 3. The conductor rotor is a composite rotor composed of copper and iron, which combines the high conductivity of copper with the high permeability of iron. This enables the PMEC to produce efficient transmission torque. The N-S pole of the PMs is alternatively distributed. The PMs rotor, the copper rotor, and the back iron rotor are coaxial, constituting a closed magnetic loop. Each pair of magnetic poles produce the same electromagnetic characteristics and mechanical properties.

Determining the electromagnetic field of the PMEC requires measuring the air gap magnetic field, which consists of both a static magnetic field produced by the PMs and the eddy current magnetic field. The superposition of the two magnetic fields constitutes the dynamic effective air gap magnetic field, which is the basis of the research for understanding PMEC performance.

In order to study the influence of structure and operation parameters on the transmission torque characteristics of the PMEC, idealization of the PMEC is as follows:

(1) There is no eddy current effect in PMs, and the PMs are uniformly magnetized in axial direction

(2) The influence of the magnetization of the back iron on the air gap magnetic field is not considered

As shown in Figure 4, a seven-layer field model is established to study the magnetic circuit of the PMEC. The PMs magnetic circuits are as follows: closed magnetic circuit between adjacent PMs passing through the copper rotor and 


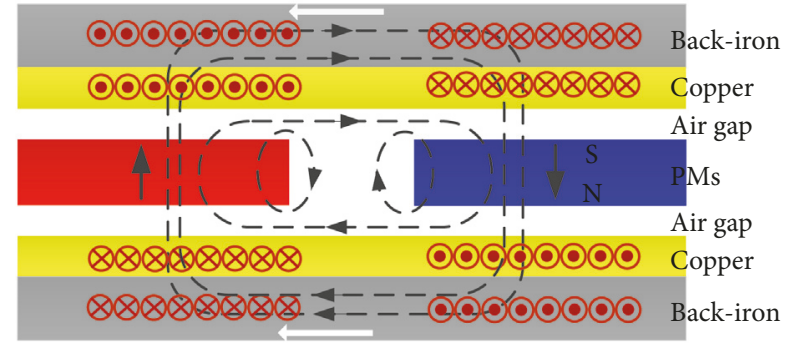

FIGURE 4: Electromagnetic field distribution of seven-layer field model.

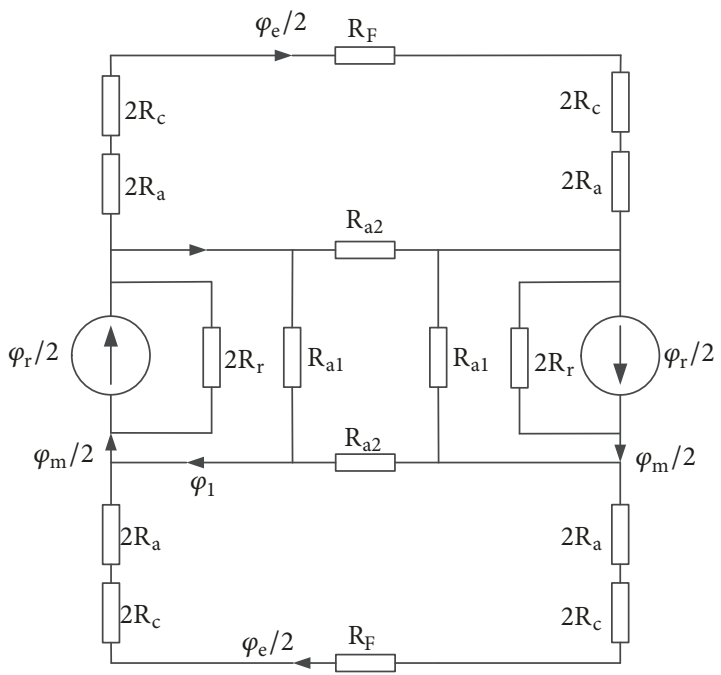

FIGURE 5: MEC diagram of the basic unit.

the back iron rotor; closed magnetic circuit between adjacent PMs passing through copper rotor or air gap; and closed magnetic circuit formed by the PM. The closed magnetic circuit passing through the copper rotor and the back iron rotor is the effective magnetic circuit, and the rest is the magnetic flux leakage. The copper rotor cuts the magnetic line with the velocity $\mathrm{V}$, and the eddy current is generated in the copper rotor. The induced eddy current field is coupled with the excitation magnetic field to form the magnetic power of transmission torque.

2.2. Static Magnetic Field Model. When the PMEC is static, the speed difference between the conductor rotor and the $\mathrm{PMs}$ rotor is zero. At this time, the PMs produce the air gap magnetic field. According to analysis of the MEC and magnetic flux, the PMs represent the current source, and the copper rotor, back iron, and air gap represent the reluctance in the magnetic circuit. Because of the symmetry of the magnetic circuit, only half the pole pairs need to be studied. The MEC diagram of the PMEC is constructed as shown in Figure 5.

The expressions of the source magnetic flux and the internal reluctance of the PM are

$$
\varphi_{r}=B_{r Z} S_{r}
$$

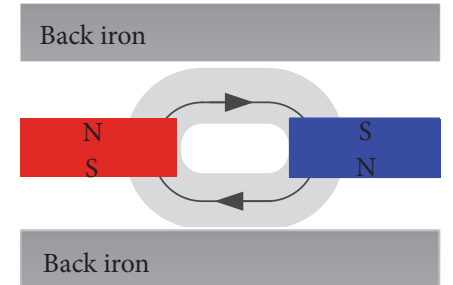

FIGURE 6: The leakage magnetic circuit of adjacent PMs.

$$
R_{r}=\frac{h_{r}}{\mu_{0} \mu_{r} S_{r}}
$$

in which $S_{r}$ is the axial area of the PM, expressed as

$$
\begin{aligned}
S_{r} & =\frac{\alpha}{2}\left(r_{2}^{2}-r_{1}^{2}\right) \\
\alpha & =\frac{\pi}{p} \frac{n}{n+1}
\end{aligned}
$$

The reluctance of the back iron rotor is as follows:

$$
R_{F}=\frac{1}{P_{F}}
$$

in which $\mathrm{P}_{\mathrm{F}}$ is the permeance of the back iron rotor, expressed as

$$
P_{F}=\int_{r_{3}}^{r_{4}} \frac{\mu_{0} \mu_{b} h_{F}}{r(\pi / p)} d r
$$

The relative permeability of air gap and the copper rotor is approximately 1 , so the reluctance of air gap and the copper rotor is as follows:

$$
R_{a c}=R_{a}+R_{c}=\frac{g+h_{c}}{\mu_{0}\left(\alpha\left(\left(r_{1}+r_{2}\right) / 2\right)\right)\left(r_{2}-r_{1}\right)}
$$

Magnetic flux leakage includes the leakage of adjacent PMs and PM leakage. The leakage magnetic circuit of adjacent PMs is shown in Figure 6.

The reluctance of the leakage magnetic of adjacent PMs is

$$
\begin{aligned}
R_{a 2} & =\frac{1}{P_{a 2}} \\
P_{a 2} & =\int_{r_{1}}^{r_{2}} \int_{0}^{x_{a 2}} \frac{\mu_{0}}{\pi x+r(\alpha / n)} d x d r
\end{aligned}
$$

in which $\mathrm{x}_{\mathrm{a} 2}$ is

$$
x_{a 2}=\min \left\{\alpha \frac{r_{1}+r_{2}}{4},\left(g+h_{c}\right)\right\}
$$

The PM leakage magnetic field is composed of lateral, inner, and outer edge magnetic leakage. The PM leakage magnetic circuit is shown in Figure 7.

The reluctance of the lateral edge flux leakage is

$$
\begin{aligned}
R_{a 11} & =\frac{1}{P_{a 11}} \\
P_{a 11} & =\int_{0}^{r_{a 11}} \frac{\mu_{0}\left(r_{2}-r_{1}\right)}{2 \pi r+h_{r}} d r
\end{aligned}
$$




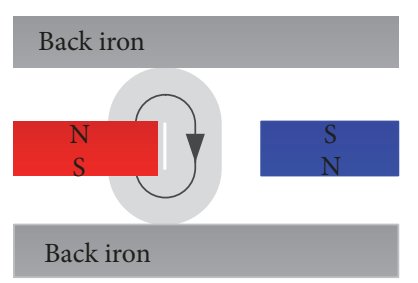

FIGURE 7: Self-leakage magnetic circuit of the PM.

in which $r_{\mathrm{a} 11}$ is

$$
r_{a 11}=\min \left\{\alpha \frac{r_{1}+r_{2}}{4}, \alpha \frac{r_{1}+r_{2}}{4 n},\left(g+h_{c}\right)\right\}
$$

The reluctance of the inner edge magnetic leakage is

$$
R_{a 12}=\frac{1}{P_{a 12}}
$$

$$
P_{a 12}=\int_{0}^{g+h_{c}} \frac{\mu_{0} \alpha r_{1}}{2 \pi r+h_{r}} d r
$$

The reluctance of the outer edge magnetic leakage is

$$
\begin{aligned}
& R_{a 13}=\frac{1}{P_{a 13}} \\
& P_{a 13}=\int_{0}^{g+h_{c}} \frac{\mu_{0} \alpha r_{2}}{2 \pi r+h_{r}} d r
\end{aligned}
$$

The reluctance of self-leakage can be expressed as

$$
\frac{2}{2 P_{a 11}+P_{a 12}+P_{a 13}}=R_{a 1}
$$

According to Figure 5 and Eq. (1)-(7), (8), (10), (11), (13), (14), (16), and (18), the effective magnetic flux $\varphi_{\mathrm{e}}$ is as follows:

$$
\varphi_{e}=\frac{R_{a 1} R_{a 2} R_{r}}{R_{r}\left[R_{a 2}\left(4 R_{a c}+R_{F}\right)+R_{a 1}\left(R_{a 2}+4 R_{a c}+R_{F}\right)\right]+R_{a 1} R_{a 2}\left(2 R_{a c}+R_{F} / 2\right)} \varphi_{r}
$$

The effective magnetic field intensity is

$$
B_{e}(\theta)= \begin{cases}B_{e}=\frac{\varphi_{e}}{S_{r}} ; & -\frac{\alpha}{2} \leq \theta \leq \frac{\alpha}{2} \\ 0 & -\frac{\pi}{2 p}<\theta<-\frac{\alpha}{2}, \frac{\alpha}{2}<\theta<\frac{\pi}{2 p}\end{cases}
$$

The relative permeability $\mu_{\mathrm{b}}$ of the back iron rotor varies with the magnetic field intensity. Therefore, $\mu_{\mathrm{b}}$ is determined by the B-H curve of the back iron rotor, as exhibited in Figure 8 .

If the thickness of back iron is too thin, magnetic saturation will occur. This increases the reluctance. The air gap flux density decreases and the transmission ability of the PMEC is reduced. If the thickness of the back iron is too thick, it does not contribute to the increase of transmission torque. On the contrary, inertia increases.

According to Figure 5 and B-H curves,

$$
\frac{\varphi_{e} / 2}{h_{F}\left(r_{2}-r_{1}\right)} \leq 1.3
$$

According to Eq. (19), $\mathrm{h}_{\mathrm{F}}$ is solved.

$$
h_{F} \geq 0.017 m
$$

Therefore, $h_{F}$ is $0.02 \mathrm{~m}$ in this paper. The relative permeability $\mu_{\mathrm{b}}$ is calculated in Figure 9 .

According to the $\mathrm{B}-\mathrm{H}$ curve of the back iron rotor, $\mu_{\mathrm{b}}$ is calculated as follows:

$$
\mu_{b}^{(k)}=\left[\frac{B^{(k)}}{\mu_{0} H^{(k)}}\right]^{0.5}\left[\mu_{b}^{(k-1)}\right]^{0.5}
$$

(see [27]). The relative permeability is judged as follows:

$$
\left|\frac{\mu_{b}^{(k)}-\mu_{b}^{(k-1)}}{\mu_{b}^{(k)}}\right| \leq 0.001
$$

(see [27]).

2.3. Dynamic Magnetic Field Model. In the operation of the PMEC, the dynamic eddy current generated on the conductor rotor is the alternating eddy current. Therefore, the inductance characteristics of the alternating eddy current should be considered. The eddy current consists of that from the copper rotor and back iron rotor. However, because the contribution to the overall eddy current from the back rotor is far less than that in the copper motor, its influence can be neglected during the rapid optimization design.

Effective magnetic fields are formed by superposing the induced magnetic field with the excited magnetic field, producing a stable, dynamic magnetic field.

$$
B_{p e}(r, \theta)=B_{e}(\theta)+B_{p}(r, \theta)
$$

The induced current density in the copper rotor is as follows:

$$
J=\sigma_{p e} \vec{v}(r, \theta) \times \vec{B}(r, \theta)=\sigma_{p e} r \omega B_{p e}(r, \theta)
$$

where $\sigma_{\text {pe }}$ is effective conductivity of copper rotor, and calculation is shown in Section 2.4. According to Ampere's law,

$$
\oint_{l} H d l=\oiint_{s} J d s
$$




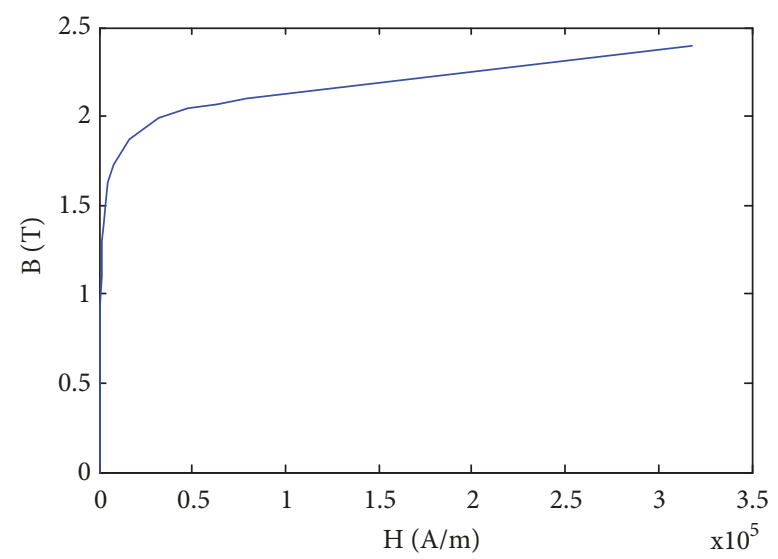

FIGURE 8: B-H curve of the back iron rotor.

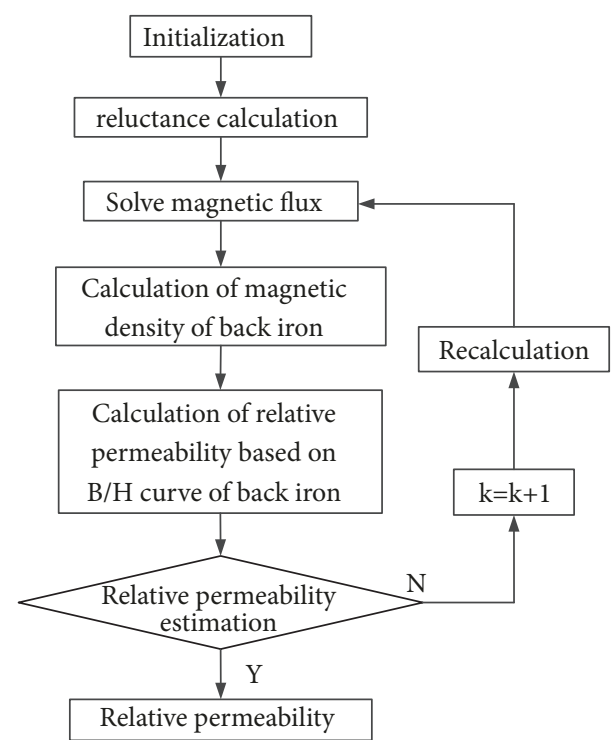

FIGURE 9: Flow chart of the relative permeability $\mu_{\mathrm{b}}$ [27].

$$
\begin{gathered}
\oint_{l} \frac{B_{p}(\theta)}{\mu_{0}} d l=\oiint_{s} \sigma_{p e} r \omega B_{p e}(\theta) d s \\
\frac{B_{p}(\theta)}{\mu_{0}} \cdot\left(2 g+2 h_{c}+h_{r}\right)=\sigma_{p e} \omega r^{2} h_{c} \int_{\theta_{1}}^{\theta_{2}} B_{p e}(\theta) d \theta
\end{gathered}
$$

$\mathrm{m}$ is the intermediate variable.

$$
m=\frac{\mu_{0} h_{c} r^{2} \sigma_{p e} \omega}{2 g+2 h_{c}+h_{r}}
$$

According to Eq. (25)-(29),

$$
B_{p}(r, \theta)=m \int_{\theta_{1}}^{\theta_{2}}\left[B_{p}(r, \theta)+B_{e}(\theta)\right] d \theta
$$

The differential of Eq. (31) is as follows:

$$
\frac{d B_{p}(r, \theta)}{d \theta}=m B_{p}(r, \theta)+m B_{e}(\theta)
$$

The general solution of $B_{p}(r, \theta)$ is derived as follows:

$$
\begin{aligned}
& B_{p}(r, \theta) \\
& \quad= \begin{cases}k_{1} e^{m \theta} & \frac{-\pi}{2 p}<\theta<\frac{-\alpha}{2}, r_{1}<r<r_{2} \\
k_{2} e^{m \theta}-B_{e} & \frac{-\alpha}{2} \leq \theta \leq \frac{\alpha}{2}, \\
k_{3} e^{m \theta} & \frac{\alpha}{2}<\theta<\frac{\pi}{2 p}, r_{1}<r<r_{2}\end{cases}
\end{aligned}
$$

$\mathrm{B}_{\mathrm{p}}(\mathrm{r}, \theta)$ satisfies the following conditions.

(a) There is a point $\theta_{0}$ in $[-\alpha / 2, \alpha / 2]$ that satisfies the following.

$$
B_{p}\left(r, \theta_{0}\right)=0
$$

(b) $\mathrm{B}_{\mathrm{p}}(\mathrm{r}, \theta)$ satisfies continuity in point $-\alpha / 2$ and $\alpha / 2$.

$$
\begin{gathered}
k_{1} e^{-\alpha m / 2}=k_{2} e^{-\alpha m / 2}-B_{e} \\
k_{3} e^{\alpha m / 2}=k_{2} e^{\alpha m / 2}-B_{e}
\end{gathered}
$$

(c) The currents on both sides of $\theta_{0}$ are equal.

$$
\int_{-\pi / 2 p}^{\theta_{0}} J h_{c} r d \theta=\int_{\theta_{0}}^{\pi / 2 p} J h_{c} r d \theta
$$

According to Eq. (34)-(37),

$$
\begin{aligned}
& k_{1}=B_{e}\left[\frac{\cosh [(m / 2 p)(\pi-\alpha p)]}{\cosh [m \pi / 2 p]}-e^{\alpha m / 2}\right] \\
& k_{2}=B_{e} \frac{\cosh [(m / 2 p)(\pi-\alpha p)]}{\cosh [m \pi / 2 p]} \\
& k_{3}=B_{e}\left[\frac{\cosh [(m / 2 p)(\pi-\alpha p)]}{\cosh [m \pi / 2 p]}-e^{-\alpha m / 2}\right] \\
& \theta_{0}=-\frac{1}{m} \ln \frac{\cosh [(m / 2 p)(\pi-\alpha p)]}{\cosh [m \pi / 2 p]}
\end{aligned}
$$




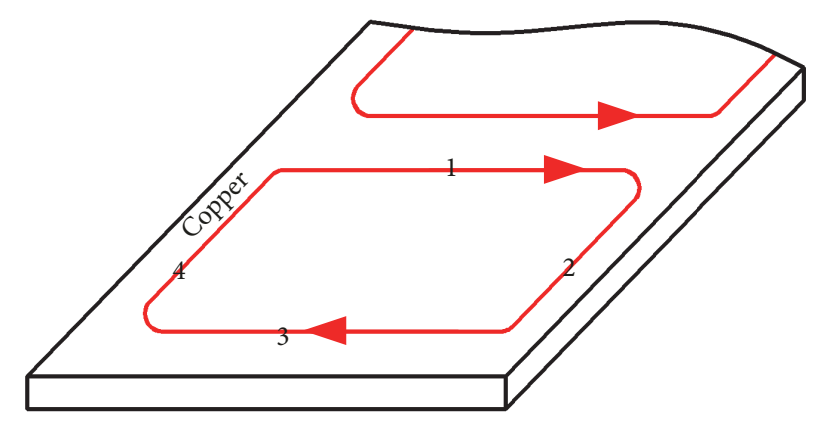

FiguRE 10: Path diagram of eddy current in the copper rotor.

$$
B_{p}(r, \theta)= \begin{cases}B_{e}\left[\frac{\cosh [(m / 2 p)(\pi-\alpha p)]}{\cosh [m \pi / 2 p]}-e^{\alpha m / 2}\right] e^{m \theta} & \frac{-\pi}{2 p}<\theta<\frac{-\alpha}{2}, r_{1}<r<r_{2} \\ B_{e} \frac{\cosh [(m / 2 p)(\pi-\alpha p)]}{\cosh [m \pi / 2 p]} e^{m \theta}-B_{e} & \frac{-\alpha}{2} \leq \theta \leq \frac{\alpha}{2}, r_{1}<r<r_{2} \\ B_{e}\left[\frac{\cosh [(m / 2 p)(\pi-\alpha p)]}{\cosh [m \pi / 2 p]}-e^{-\alpha m / 2}\right] e^{m \theta} & \frac{\alpha}{2}<\theta<\frac{\pi}{2 p}, r_{1}<r<r_{2}\end{cases}
$$

2.4. Effective Conductivity of the Copper Rotor. The eddy current distribution of the copper rotor is shown in Figure 10. The Greenhouse method is the piecewise superposition algorithm, which can accurately calculate eddy current inductance. However, there are many superposition operations in this algorithm, which makes the computational efficiency low $[41,42]$. In order to simplify the calculation of inductance, Jenei et al. improve the Greenhouse method [42]. The Jenei method is the global average algorithm. In contrast, the Jenei method can predict inductance accurately, but its operation efficiency is higher than the Greenhouse method.

$$
l=\frac{l_{1}+l_{2}+l_{3}+l_{4}}{4}
$$

in which $l_{i}$ is the effective length of the $i$ segment conductor.

According to the Jenei method, inductance is calculated as follows:

$$
L_{c}=\frac{\mu_{0} l}{2 \pi}\left[\ln \frac{l}{h_{c}+r_{A V} \alpha / 2}-0.67\right]
$$

in which $r_{A V}=\left(r_{1}+r_{2}\right) / 2$.

The calculation for impedance is as follows:

$$
\begin{aligned}
Z_{c} & =R_{z c}+j X L_{c} \\
R_{Z C} & =\frac{2 l}{\sigma_{c} \alpha r_{A V} h_{c}} \\
X & =2 \pi f=\frac{\pi p s N_{1}}{15}
\end{aligned}
$$

$$
\begin{aligned}
\left|Z_{c}\right| & =\sqrt{\left(\frac{2 l}{\sigma_{c} \alpha r_{A V} h_{c}}\right)^{2}+\left(\frac{\pi p s N_{1} L_{c}}{15}\right)^{2}} \\
\cos \varphi_{R_{Z C}} & =\frac{R_{Z C}}{\left|Z_{c}\right|} \\
s & =\frac{N_{1}-N_{2}}{N_{1}}
\end{aligned}
$$

Therefore, the equivalent conductivity is calculated as follows:

$$
\begin{aligned}
\left|Z_{c}\right| & =\frac{2 l}{\sigma_{p e} \alpha r_{A V} h_{c}} \\
\frac{1}{\sigma_{p e}} & =\sqrt{\left(\frac{1}{\sigma_{c}}\right)^{2}+\left(\frac{\pi p s N_{1} L_{c} \alpha r_{A V} h_{c}}{30 l}\right)^{2}}
\end{aligned}
$$

The relationship between $Z_{c}$ and slip is shown in Figure 11. The inductance of copper increases rapidly and the equivalent conductivity decreases rapidly. As slip increases, the characteristic copper inductance also increases. However, because the characteristic resistance remains unchanged, the equivalent conductivity is formed by both the inductance and the resistance. As such, the reduction of the equivalent conductivity gradually slows down.

\section{Torque Model}

According to the analysis of the dynamic magnetic field, the magnetic coupling force provides traction for torque transmission. Therefore, the output torque is expressed as follows [28, 29]:

$$
T=4 p k_{s} \cos \varphi_{R_{Z C}} \int_{V} r|J \times B| d V
$$




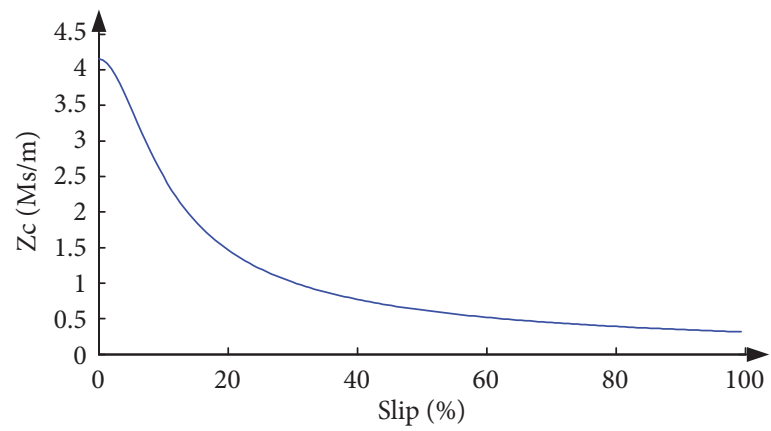

FIGURE 11: $Z_{c}$-slip curve diagram.

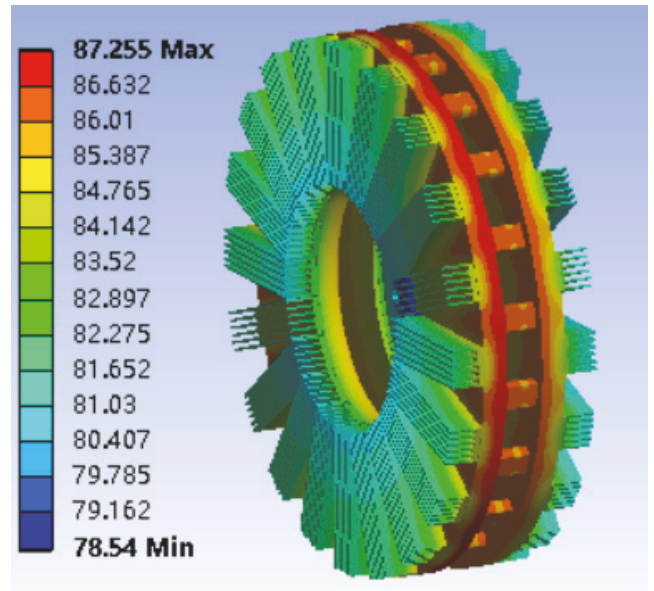

Figure 12: Temperature distribution of the PMEC.

where $\mathrm{k}_{\mathrm{s}}$ is Russell-Norsworthy factor [28], the correction factor of eddy boundary effect, as calculated below:

$$
k_{s}=1-\frac{\tanh \left[p\left(r_{2}-r_{1}\right) /(2 r)\right]}{p\left(r_{2}-r_{1}\right) /(2 r)\left\{1+\tanh \left[p\left(r_{2}-r_{1}\right) /(2 r)\right] \tanh \left[p\left(r_{4}-r_{3}-r_{2}+r_{1}\right) /(2 r)\right]\right\}}
$$

The 3D integral process of space electromagnetic field is complex, which is unfavorable for rapid optimization design. The validity of the average radius for solving the output torque has been proved in the literature [25-30]. Therefore, the output torque is as follows:

$$
\begin{aligned}
T= & 4 p k_{s} r_{A V}^{3}\left(r_{2}-r_{1}\right) h_{c} \sigma_{p e} \omega \cos \varphi_{R_{Z C}} \\
& \cdot \int_{-\pi / 2 p}^{\pi / 2 p} B_{p e}^{2}\left(r_{A V}, \theta\right) d \theta
\end{aligned}
$$

\section{Model Verification}

The structure of the PMEC is shown in Figure 2. The PM adopts $\mathrm{NdFeB}$. The conductor rotor is constructed with copper and steel 10 . The main structural parameters of the PMEC are shown in Table 1.
Torque value is related to the temperature, and the eddy current loss produces heat [29]. Therefore, the air-cooling fin is designed according to the heat power of the PMEC. The thermodynamic analysis of the PMEC is carried out by ANSYS. The structure of the air-cooling fin is optimized, so that the working temperature of the copper rotor is about $90^{\circ} \mathrm{C}$. The simulation results are shown in Figure 12 .

4.1. Study on the Distribution of Electromagnetic Field. In literature $[3,4]$, the validity of the FEM is verified by comparative study of FEM and experiment. Therefore, the proposed model is compared with the FEM. $B_{r z}$ is the magnetic flux density of the PM in the $\mathrm{Z}$ direction, and it is extracted along $r$ direction as shown in Figure 13. The average value of $B_{r z}$ is taken as the input value of the proposed model.

In the static state, the speed difference between the conductor rotor and the PMs rotor is 0 . The effective magnetic 
TABLE 1: The structural parameters of the PMEC.

\begin{tabular}{lccc}
\hline Parameter & value & Parameter & value \\
\hline Inner radius of the PMs $[\mathrm{m}]$ & 0.1775 & Inner radius of conductor rotor $[\mathrm{m}]$ & 0.15 \\
\hline Outer radius of the PMs $[\mathrm{m}]$ & 0.2625 & Outer radius of conductor rotor $[\mathrm{m}]$ & 0.3 \\
\hline Thickness of the PMs $[\mathrm{m}]$ & 0.032 & Thickness of the copper rotor $[\mathrm{m}]$ & 0.009 \\
\hline Thickness of the PMs & 10 & Thickness of the back iron rotor $[\mathrm{m}]$ & 0.02 \\
\hline Remanence of the PMs $[\mathrm{T}]$ & 1.2 & Conductivity of the copper rotor $\left[20^{\circ} \mathrm{C}\right]\left[\mathrm{M}_{\mathrm{S}} / \mathrm{m}\right]$ & 57.1 \\
\hline
\end{tabular}

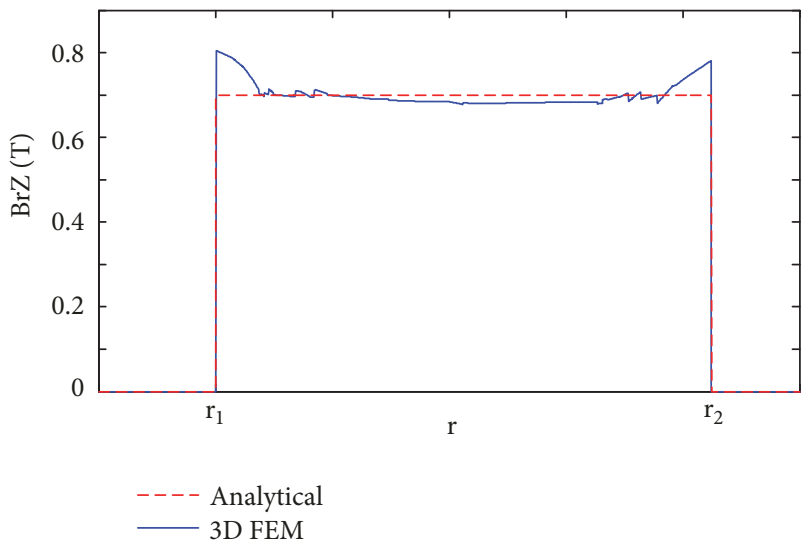

FIGURE 13: Distribution of magnetic flux density of the PM.

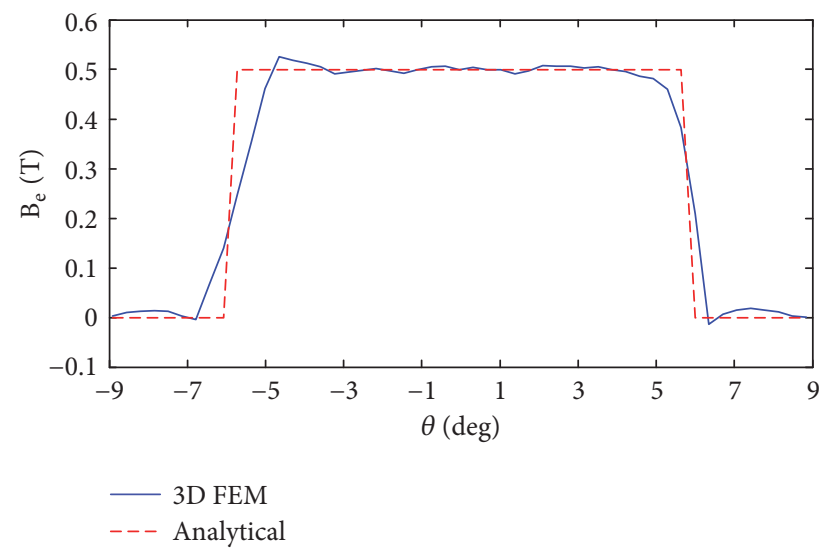

Figure 14: Air gap flux density distribution curve at 0 speed difference.

flux density distribution of the air gap is shown in Figure 14. The magnetic flux density distribution is relatively uniform in $[-\alpha / 2, \alpha / 2]$ and is almost zero in other intervals. The average error between the theoretical and FEM data is 3.4\%.

In the operation state, there is a speed difference between the conductor rotor and the PMs rotor. The effective magnetic flux density distribution of the air gap is exhibited in Figure 15 at a 50rpm difference in speed. The air gap magnetic induction intensity gradually increases in $[-\alpha / 2, \alpha / 2]$. The magnetic induction intensity is about $-0.1 \mathrm{~T}$ in $[-\pi / 2 \mathrm{p},-\alpha / 2]$, and it is about $0.1 \mathrm{~T}$ in $[\alpha / 2, \pi / 2 \mathrm{p}]$. The deviations between the theoretical and FEM data are less than $3.7 \%$.

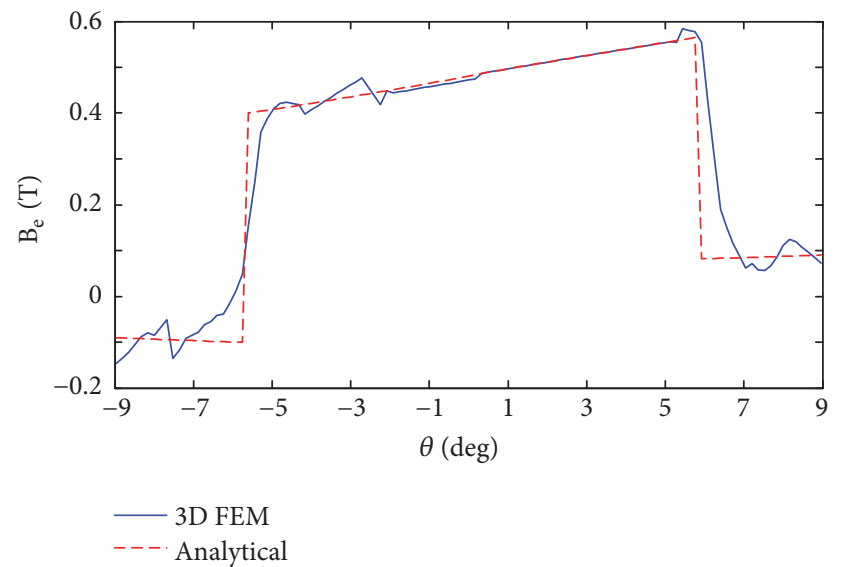

FIGURE 15: Air gap flux density distribution curve at 50rpm speed difference.

The eddy current distribution at a $50 \mathrm{rpm}$ speed difference is shown in Figure 16. The position of the eddy current ring corresponds to that of the PMs. The induced magnetic field is produced by the eddy current field. By comparing the data from Figures 14 and 15, it is found that the induced magnetic field weakens the excitation magnetic field in the first half of the period and strengthens it in the latter half of the period. As the speed difference also increases, the effect of the induced magnetic field on the excitation magnetic field is strengthened.

4.2. Study on the Influence of Slip on Transmission Performance. Based on the structural parameters in Table 1, the PMEC was established, and an experimental platform was built as shown in Figure 17. The conductor rotor is symmetrically distributed on both sides of the PMs rotor. The power equipment adopts the gear motor. The torque was tested in the range of $5 \%$ slip. The effect of different slip on torque was studied by changing the thickness of air gap.

When the air gap is $0.004 \mathrm{~m}$, the variation of torque is as shown in Figure 18. When the air gap is $0.002 \mathrm{~m}$, the variation of torque is shown in Figure 19. The predicted torque model is compared with the 3D FEM and the experiment in the range of $5 \%$ slip. The results show that difference between theoretical and experimental data is always below $4.5 \%$. Theoretical torque data based only on the resistance characteristics of the copper rotor is compared to FEM and experimental data. This data shows that, at low slip, the model agrees well, whereas torque error increases as slip also increases. When the slip 


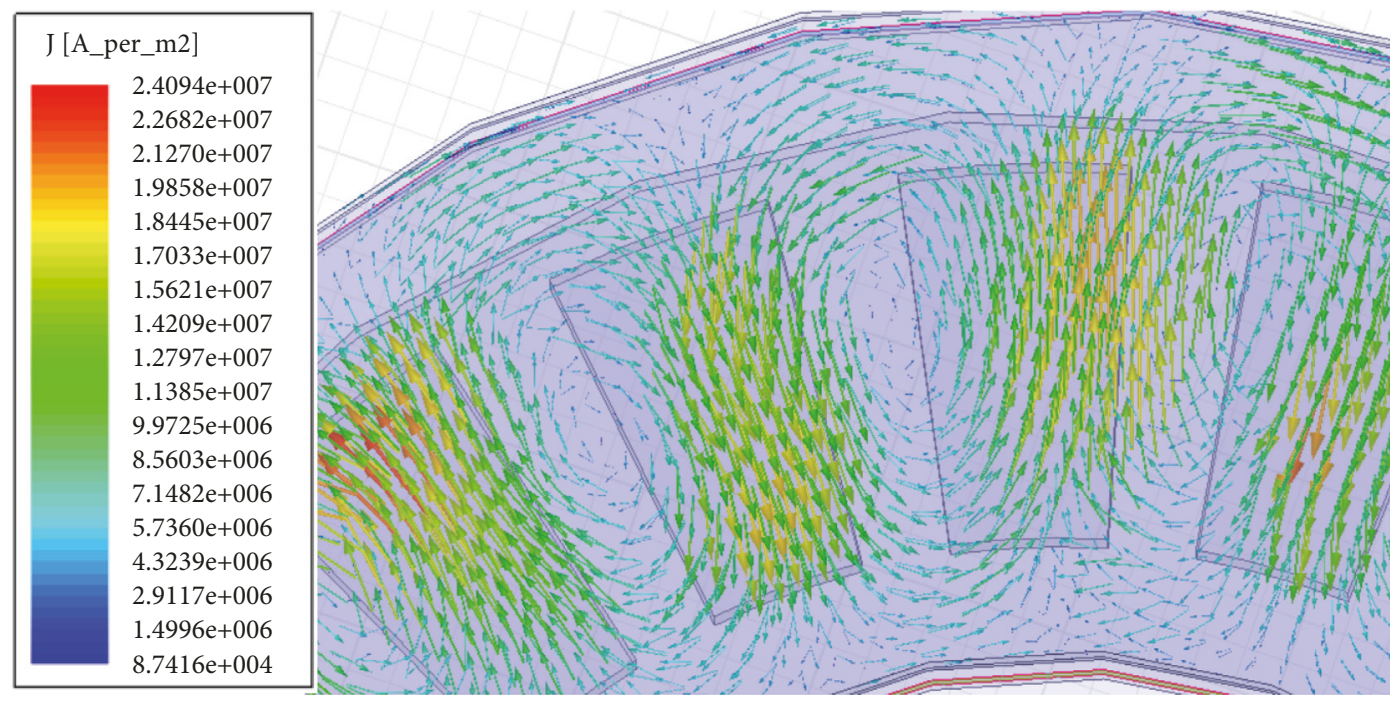

FIGURE 16: Eddy current distribution at 50rpm speed difference.

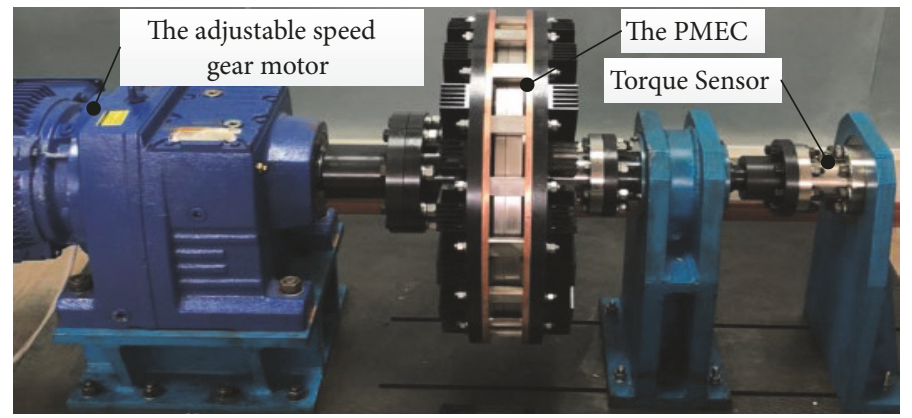

FIGURE 17: Experimental platform.

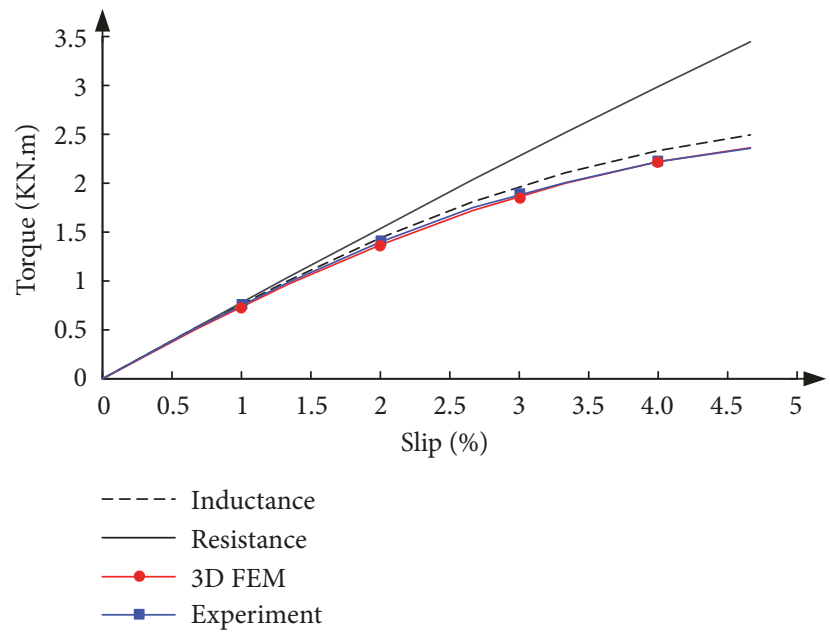

FIgURE 18: The torque curve of the PMEC $(\mathrm{g}=0.004 \mathrm{~m})$.

is $4.7 \%$, the error reaches $40 \%$. The reason is that, with the increase of slip, the inductance effect of the copper rotor is enhanced, which makes the theoretical error increase.
The torque-slip curve when the air gap is $0.004 \mathrm{~m}$ is shown in Figure 20. The theoretical data are in good agreement with 3D FEM data at $0-100 \%$ slip where the deviations between the theoretical data and the FEM data are less than 5\%, also showing that the validity of the proposed torque model is proved in the $100 \%$ slip. In the range of $0-8 \%$ slip, the torque rapidly increases with the increase of slip. In the range of $8-100 \%$ slip, the torque decreases rapidly in the initial stage before stabilizing.

Based on the analysis in Section 4.1, the induced magnetic field affects the distribution of the excitation magnetic field. This influence is strengthened as slip increases. The cutting speed of the copper rotor is proportional to slip. In the initial stage of slip, the cutting speed of the copper rotor increases, and the induced potential increases rapidly in the copper rotor. Although the equivalent conductivity of the copper rotor decreases, the eddy current field strengthens as does the intensity of the induced magnetic field. At this time, the induced magnetic field has little influence on the intensity of the excitation magnetic field, so the coupling force between the induction magnetic field and the excitation magnetic field is enhanced. The torque transmission ability of the PMEC increases rapidly. As the induced magnetic 
TABLE 2: Table of relation between the pole pairs and torque $(\mathrm{g}=0.004 \mathrm{~m})$.

\begin{tabular}{|c|c|c|c|c|c|c|}
\hline \multirow[t]{2}{*}{$\mathrm{p}$} & \multicolumn{3}{|c|}{ Analytical } & \multicolumn{3}{|c|}{ 3D FEM } \\
\hline & $4 \%$ & $6 \%$ & $8 \%$ & $4 \%$ & $6 \%$ & $8 \%$ \\
\hline 6 & 1899 & 2162 & 2159 & 1805 & 2072 & 2124 \\
\hline 8 & 2229 & 2570 & 2589 & 2125 & 2468 & 2535 \\
\hline 10 & 2346 & 2692 & 2702 & 2235 & 2600 & 2638 \\
\hline 12 & 2355 & 2660 & 2639 & 2271 & 2595 & 2612 \\
\hline 14 & 2327 & 2604 & 2562 & 2225 & 2549 & 2541 \\
\hline 16 & 2283 & 2560 & 2521 & 2203 & 2470 & 2437 \\
\hline
\end{tabular}

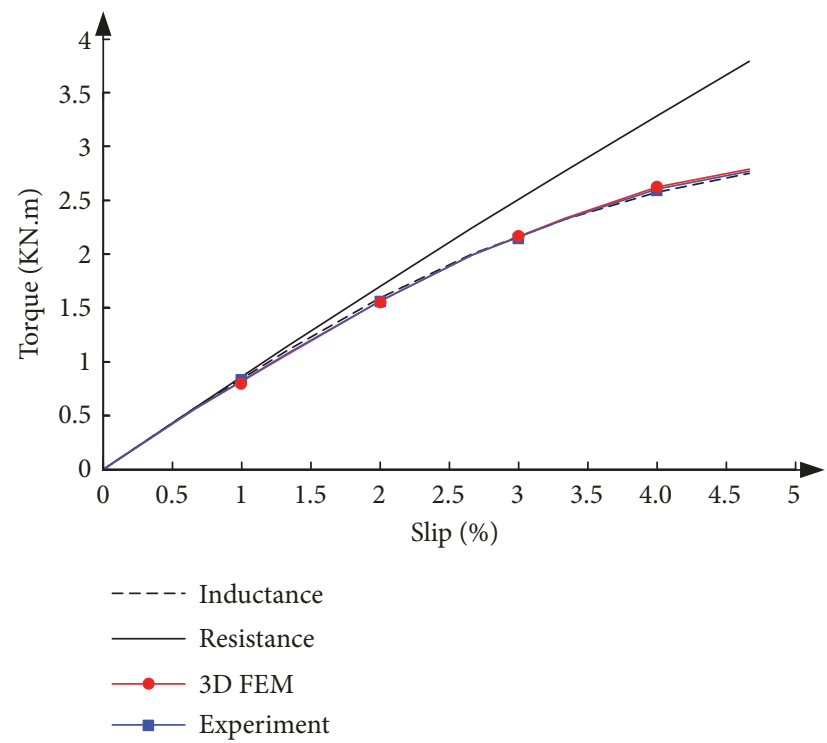

Figure 19: The torque curve of the PMEC $(g=0.002 \mathrm{~m})$.

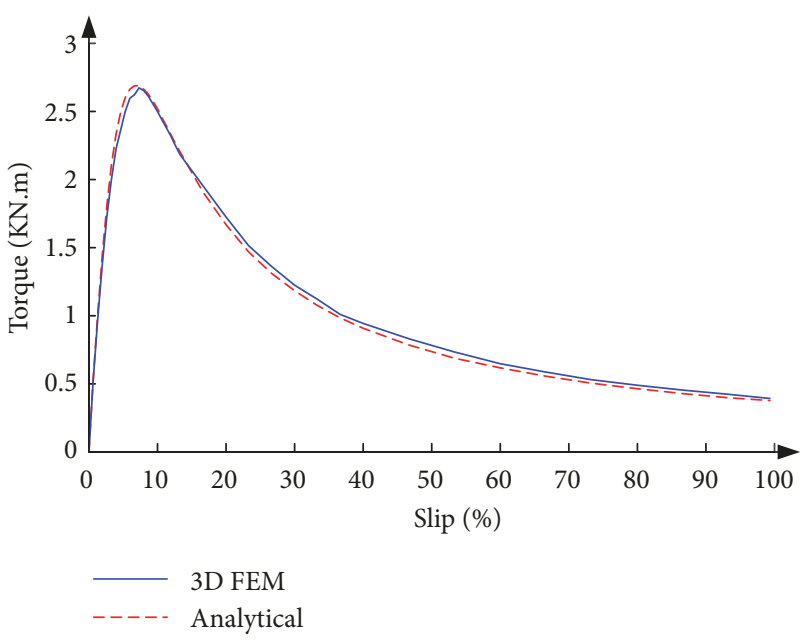

Figure 20: The torque curve of the PMEC $(\mathrm{g}=0.004 \mathrm{~m})$.

field increases, the intensity of excitation magnetic field is continuously weakened, which is clearly observed when the slip exceeds $8 \%$. As slip increases, the increase of induction potential is limited, and the equivalent conductivity decreases

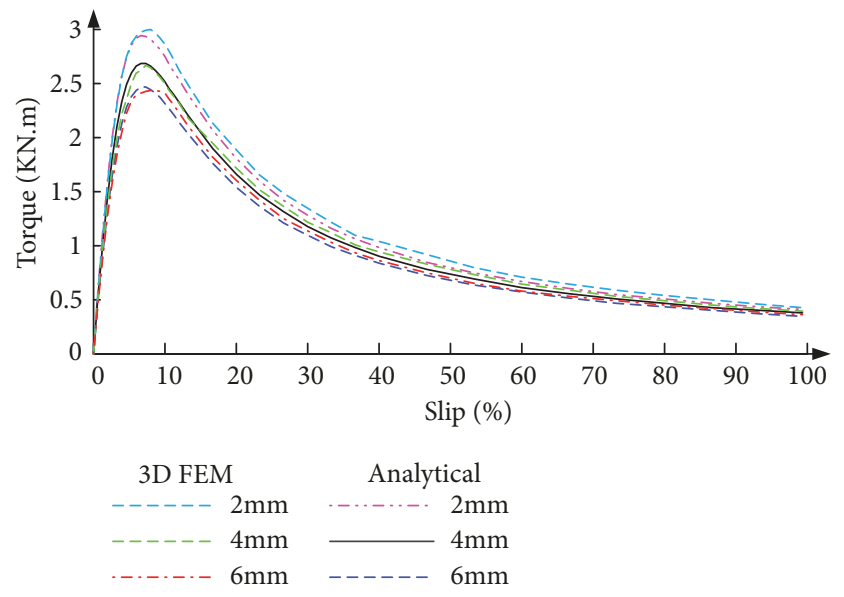

FIgURE 21: Transmission characteristic curves at different air gaps.

rapidly. This reduces the intensity of the induced magnetic field. Therefore, the magnetic coupling force decreases and the torque transmission ability drops rapidly. When the slip exceeds $20 \%$, both the equivalent conductivity and torque transmission decrease slowly and eventually stabilize.

4.3. Study on the Influence of Structural Parameters on Transmission Performance. (A) Study on the Influence of Air Gap on Transmission Performance. The thickness of the air gap was changed, and the effect of air gap on transmission performance was studied. As shown in Figure 21, with the decrease of the air gap, the torque transmission ability of the PMEC increased, and the peak value of torque was greatly improved. As the air gap decreased, the leakage of the PM decreased, which made the intensity of the excitation magnetic field increase, so the torque transmission ability was enhanced. The deviations between the theoretical data and the FEM data were always below 5\%.

(B) Study on the Influence of Pole Pairs on Transmission Performance. The number of pole pairs was changed, and the total volume of the PMs remained unchanged. The effect of pole pairs on transmission performance was studied. The results are shown in Table 2, showing that the best number of pole pairs is 10 or 12 . When the number of pole pairs is less than 10 , the transmission torque ability increases obviously. 
TABLE 3: Table of relation between the thickness of the copper rotor and torque $(\mathrm{g}=0.004 \mathrm{~m})$.

$h_{c}$

\begin{tabular}{ll} 
& $4 \%$ \\
\hline 0.006 & 2053 \\
\hline 0.007 & 2186 \\
\hline 0.008 & 2280 \\
\hline 0.009 & 2346 \\
\hline 0.01 & 2363 \\
\hline 0.011 & 2360 \\
\hline 0.012 & 2347 \\
\hline
\end{tabular}

Analytical

\begin{tabular}{cccc}
$4 \%$ & $6 \%$ & $4 \%$ & $6 \%$ \\
\hline 2053 & 2577 & 1966 & 2559 \\
\hline 2186 & 2660 & 2102 & 2662 \\
\hline 2280 & 2689 & 2167 & 2660 \\
\hline 2346 & 2692 & 2235 & 2600 \\
\hline 2363 & 2621 & 2266 & 2528 \\
\hline 2360 & 2538 & 2229 & 2443 \\
\hline 2347 & 2462 & 2221 & 2344 \\
\hline
\end{tabular}

\begin{tabular}{lcccccr}
\hline & & \multicolumn{2}{c}{$\mathrm{s}$} & 3D FEM \\
$\mathrm{h}_{\mathrm{r}}$ & Analytical & $6 \%$ & $2 \%$ & $4 \%$ & $6 \%$ \\
\hline 0.026 & $2 \%$ & $4 \%$ & 2421 & 1240 & 2030 & 2334 \\
\hline 0.028 & 1306 & 2121 & 2521 & 1279 & 2096 & 2522 \\
\hline 0.03 & 1353 & 2202 & 2610 & 1332 & 2158 & 2600 \\
\hline 0.032 & 1396 & 2275 & 2692 & 1372 & 2235 & 2719 \\
\hline 0.034 & 1435 & 2346 & 2772 & 1406 & 2310 & 2354 \\
\hline 0.036 & 1470 & 2406 & 2845 & 1429 & & \\
\hline
\end{tabular}

TABLE 5: Table of relation between the $\mathrm{T}_{0}$ and torque.

$\mathrm{h}_{\mathrm{r}}$

\begin{tabular}{ll} 
& $2 \%$ \\
\hline 0.026 & 50.1 \\
\hline 0.028 & 48.3 \\
\hline 0.03 & 46.5 \\
\hline 0.032 & 44.8 \\
\hline 0.034 & 43.2 \\
\hline 0.036 & 41.8 \\
\hline
\end{tabular}

Analytical

\begin{tabular}{lllll}
$4 \%$ & $6 \%$ & $2 \%$ & $4 \%$ & $6 \%$ \\
\hline 81.5 & 93.1 & 47.7 & 78.1 & 89.7 \\
\hline 78.6 & 90.0 & 45.6 & 74.8 & 86.8 \\
\hline 75.8 & 87.0 & 44.4 & 71.9 & 84.1 \\
\hline 73.3 & 84.1 & 42.9 & 69.8 & 81.2 \\
\hline 70.7 & 81.5 & 41.3 & 67.9 & 78.8 \\
\hline 68.5 & 79.0 & 39.7 & 65.4 & 75.5 \\
\hline
\end{tabular}

When the number is more than 12 , the transmission torque ability decreases significantly. This is because the distance of the PM decreases with the increase of the pole pairs, which increases the flux leakage of the PM. Thus the transmission torque ability of the PMEC decreases.

(C) Study on the Influence of the Thickness of the Copper Rotor on Transmission Performance. The influence of the thickness of the copper rotor on transmission performance was studied as shown in Table 3. As the thickness of the copper rotor increased to $0.009 \mathrm{~m}$, the transmission torque of the PMEC increased and eventually leveled off. When the thickness was higher than $0.01 \mathrm{~m}$, the transmission torque ability increased slightly. Therefore, when the thickness of the copper rotor is $0.009 \sim 0.01 \mathrm{~m}$, transmit torsion for the PMEC is optimized.

When the thickness is less than $0.009 \mathrm{~m}$, the thickness of the copper has little influence on the magnetic leakage of the PMs. Increasing the thickness is beneficial to enhancing the eddy current magnetic field and the magnetic coupling force. Therefore, the transmission torque ability is enhanced. When the thickness is greater than $0.01 \mathrm{~m}$, the leakage increases and the effective air gap magnetic field decreases; thus the transmission torque ability of the PMEC decreases.

(D) Study on the Influence of Thickness of the PM on Transmission Performance. The thickness of permanent magnets was changed, and the remaining parameters are shown in Table 1. As shown in Table 4, the results show that the thickness of the PM is positively correlated with the transmission torque ability of the PMEC. The deviations between the theoretical data and the FEM data are always below 5.3\%. The validity of the proposed model was therefore verified.

$\mathrm{T}_{0}$ is the value of torque under unit thickness of the PMs, $\mathrm{T}_{0}=\mathrm{T} / 1000 \mathrm{~h}_{\mathrm{r}}$, and $\mathrm{T}_{0}$ is used to measure the utilization rate of the PMs. As shown in Table 5, with the increase of the thickness of the PMs, the contribution of the PMs 


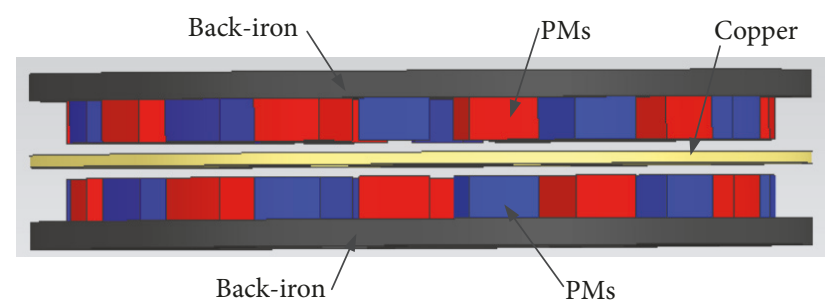

Figure 22: Structural diagram of the double-sided PM eddy current coupler.

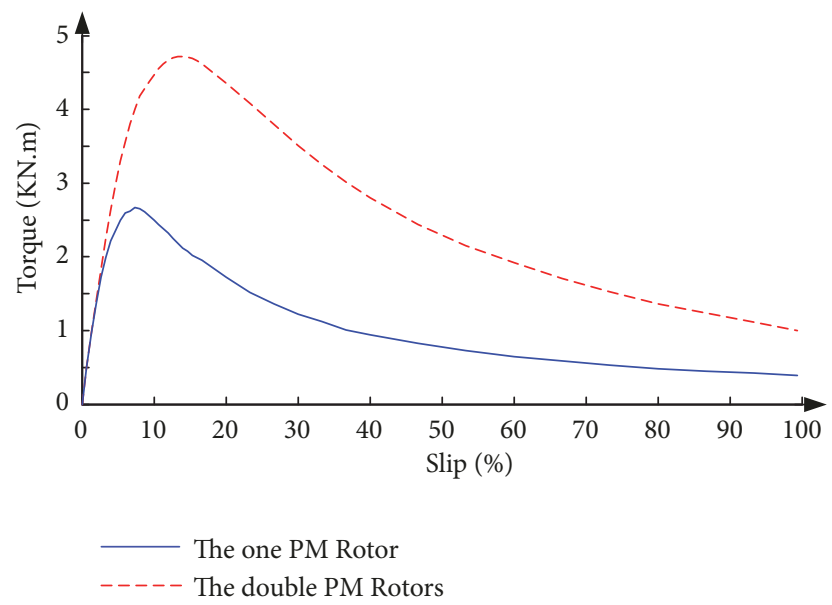

Figure 23: Comparison of transmission characteristics ( $g=0.004 \mathrm{~m})$.

to the transmission torque ability of the PMEC decreases. The reason for this phenomenon is that as the thickness of the PMs increased, so does leakage, thereby decreasing the contribution of the PMs to the effective air gap magnetic field as well as transmission torque. Therefore, the thickness of the PMs is negatively correlated with the utilization ratio of the PMs.

(E) Comparative Study with the Double-Sided PM Eddy Current Coupler. The double-sided PM eddy current coupler is shown in Figure 22. The main structural parameters of the double-sided PM eddy current coupler are consistent with those in Table 1. By 3D FEM, the transmission torque ability of the PMEC studied in this study was compared with that of the double-sided PM eddy current coupler as shown in Figure 23. The peak torque of the double-sided PM eddy current coupler is increased by 1.6 times. The utilization ratio of the PMs decreases. The torque value increases by 2.6 times under $100 \%$ slip. The increase of torque value is greater under $100 \%$ slip. When the load is blocked, the slip between the motor and the load is $100 \%$. The PMEC becomes the load of the motor. The torque value transmitted by the PMEC is the output torque value of the motor. Torque value under $100 \%$ slip should be as small as possible. Therefore, the PMEC studied in this paper has more advantages than the doublesided PM eddy current coupler.

\section{Conclusion}

Based on MEC, combining Faraday's law, Ampere's law, and Jenei method, a simple and practical 3D nonlinear model is proposed to predict the magnetic field distribution and transmission characteristics of the PMEC. The theoretical data, 3D FEM data, and experiment data are comparatively studied. The validity of the model is verified in the range of $0 \sim$ $100 \%$ slip. The proposed theoretical model can quickly study the influence of structural parameters on the transmission performance of the PMEC.

(1)The slip is less than $8 \%$, the transmission torque ability is positively correlated with the slip, the slip is higher than $8 \%$, and the transmission torque ability is negatively correlated with the slip.

(2)The thickness of air gap and the PMs are the two most obvious parameters affecting the transmission torque ability of the PMEC. The thickness of air gap is negatively correlated and the thickness of the PMs is positively correlated.

(3)The thickness of the PMs is negatively correlated with the utilization ratio of the PMs. Therefore, the thickness of the PMs should not be too thick.

(4)When the number of pole pairs is greater than 12 pairs, with the increase of the number of pole pairs, the transmission torque ability decreases. The optimal number of magnetic poles is 10 or 12 .

(5) The thickness of copper rotor is $0.009-0.01 \mathrm{~m}$. If the thickness of the copper rotor is too thick or too thin, the transmission torque of the PMEC will decrease.

In addition, the PMEC of double conductor rotors is compared with the double-sided PM eddy current coupler, and the advantages of double conductor rotors structure are verified.

\section{Nomenclature}

$\mathrm{h}_{\mathrm{r}}$ : Thickness of the PMs [m]

$h_{c}$ : Thickness of the copper rotor $[\mathrm{m}]$

$\mathrm{h}_{\mathrm{F}}$ : Thickness of the back iron rotor $[\mathrm{m}]$

g: Thickness of the air gap [m]

$\mathrm{r}_{1}$ : Inner radius of the PMs [m]

$\mathrm{r}_{2}$ : Outer radius of the PMs $[\mathrm{m}]$

$\mathrm{r}_{3}$ : Inner radius of conductor rotor $[\mathrm{m}]$

$\mathrm{r}_{4}$ : Outer radius of conductor rotor $[\mathrm{m}]$

$\mathrm{N}_{1}$ : Rotation speed of the conductor rotor [rpm]

$\mathrm{N}_{2}$ : Rotation speed of the PMs rotor [rpm]

V: Relative velocity between conductor rotor and the $\mathrm{PMs}$ rotor $[\mathrm{m} / \mathrm{s}]$

s: Slip ratio between eddy current rotor and the PMs rotor

$\mathrm{R}_{\mathrm{r}}$ : Reluctance of the PMs $\left[\mathrm{H}^{-1}\right]$

$\mathrm{R}_{\mathrm{c}}$ : Reluctance of the copper rotor $\left[\mathrm{H}^{-1}\right]$

$\mathrm{R}_{\mathrm{F}}$ : Reluctance of the back iron rotor $\left[\mathrm{H}^{-1}\right]$

$\mathrm{R}_{\mathrm{a}}$ : Reluctance of the air gap $\left[\mathrm{H}^{-1}\right]$

$\mathrm{R}_{1}$ : Reluctance of the magnetic flux leakage $\left[\mathrm{H}^{-1}\right]$

$\mathrm{R}_{\mathrm{a} 1}$ : Reluctance of the PM self-leakage $\left[\mathrm{H}^{-1}\right]$

$\mathrm{R}_{\mathrm{a} 2}$ : Reluctance between the surfaces of adjacent PMs $\left[\mathrm{H}^{-1}\right]$ 
$\varphi_{\mathrm{r}}: \quad$ Flux source of the PMs $[\mathrm{Wb}]$

$\varphi_{\mathrm{m}}:$ Flux through the PMs [Wb]

$\varphi_{1}$ : Flux leakage of the PMs [Wb]

$\varphi_{\mathrm{e}}$ : Effective flux through the conductor rotor $[\mathrm{Wb}]$

$\alpha$ : The angle of the PM in the circumferential direction

$\mathrm{n}$ : The ratio between the PMs and residual space

$\mathrm{S}_{\mathrm{r}}$ : Surface area of the PMs $\left[\mathrm{m}^{2}\right]$

$\mathrm{r}_{\mathrm{av}}$ : Average distribution radius of PM [m]

p: Number of pole pairs

$\mu_{0}$ : Vacuum permeability $[\mathrm{H} / \mathrm{m}]$

$\mu_{\mathrm{b}}$ : Relative permeability of the back iron

$\mu_{\mathrm{r}}$ : Relative permeability of the PMs

$\mathrm{B}_{\mathrm{r}}$ : Remanence of the PMs [T]

$\mathrm{B}_{\mathrm{rz}}$ : Remanence of the PMs in $\mathrm{Z}$ direction [T]

$\mathrm{B}_{\mathrm{e}}$ : Static effective magnetic field intensity [T]

$\mathrm{B}_{\mathrm{p}}$ : Induced magnetic field intensity $[\mathrm{T}]$

$\mathrm{B}_{\mathrm{pe}}$ : Dynamic coupling magnetic field intensity [T]

$\sigma_{\mathrm{c}}$ : Conductivity of the copper rotor $[\mathrm{Ms} / \mathrm{m}]$

$\sigma_{\mathrm{pe}}:$ Effective conductivity of the copper rotor $[\mathrm{Ms} / \mathrm{m}]$

$\omega: \quad$ Relative angular velocity ( $\mathrm{rad} / \mathrm{s})$

$\mathrm{R}_{\mathrm{ZC}}$ : Resistance of the copper rotor $[\Omega]$.

\section{Data Availability}

The data used to support the findings of this study are included within the article.

\section{Disclosure}

The authors state that the theoretical analysis data, finite element analysis data, and experimental data are reliable.

\section{Conflicts of Interest}

The authors declare that they have no conflicts of interest.

\section{Acknowledgments}

The authors express their sincere gratitude for the support by the National Natural Science Foundation of China (Grant No 11872006) and Beihang University.

\section{References}

[1] B. Li, H. Ma, X. Yu, J. Zeng, X. Guo, and B. Wen, "Nonlinear vibration and dynamic stability analysis of rotor-blade system with nonlinear supports," Archive of Applied Mechanics.

[2] C. J. Zhang, Y. S. Ren, and S. J. Ji, "Research on lateral nonlinear vibration behavior of composite shaft-disk rotor system," Applied Mechanics and Materials, vol. 875, pp. 149-161, 2018.

[3] Z. Li, D. Wang, D. Zheng, and L. Yu, "Analytical modeling and analysis of magnetic field and torque for novel axial flux eddy current couplers with PM excitation," AIP Advances, vol. 7, no. 10, 2017.

[4] H.-J. Shin, J.-Y. Choi, S.-M. Jang, and K.-Y. Lim, "Design and analysis of axial permanent Magnet couplings based on 3D
FEM," IEEE Transactions on Magnetics, vol. 49, no. 7, pp. 39853988, 2013.

[5] G.-H. Jang, J.-M. Kim, H.-J. Shin, and J.-Y. Choi, "Optimal design and torque analysis considering eddy-current reduction of axial-flux permanent magnet couplings with Halbach array based on 3D-FEM," in Proceedings of the IEEE Conference on Electromagnetic Field Computation(CEFC), 2016.

[6] S. Anwar, "A parametric model of an eddy current electric machine for automotive braking applications," IEEE Transactions on Control Systems Technology, vol. 12, no. 3, pp. 422-427, 2004.

[7] J. Fontchastagner, T. Lubin, and D. Netter, "Axial-field eddycurrent coupling: a 3D test problem for numerical experiments," International Journal of Numerical Modelling: Electronic Networks, Devices and Fields, vol. 31, no. 2, 2018.

[8] G.-H. Jang, J.-M. Kim, H.-J. Shin, and J.-Y. Choi, "Optimal design and torque analysis considering eddy-current reduction of axial-flux permanent magnet couplings with Halbach array based on 3D-FEM," in Proceedings of the Magnetics Conference, 2017.

[9] L. Mo, X. Zhu, T. Zhang, L. Quan, Y. Wang, and J. Huang, "Temperature rise calculation of a flux-switching permanentmagnet double-rotor machine using electromagnetic-thermal coupling analysis," IEEE Transactions on Magnetics, vol. 54, no. 3, 2018.

[10] Y. Zhang, S. McLoone, W. Cao, F. Qiu, and C. Gerada, "Power Loss and Thermal Analysis of a MW High-Speed Permanent Magnet Synchronous Machine," IEEE Transactions on Energy Conversion, vol. 32, no. 4, pp. 1468-1478, 2017.

[11] J. Choi and S. Jang, "Analytical magnetic torque calculations and experimental testing of radial flux permanent magnet-type eddy current brakes," Journal of Applied Physics, vol. 111, no. 7, p. 07E712, 2012.

[12] C. W. Trowbridge and J. K. Sykulski, "Some key developments in computational electromagnetics and their attribution," IEEE Transactions on Magnetics, vol. 42, no. 4, pp. 503-508, 2006.

[13] C. Tian, Y. Zhong, L. Wei et al., "A coupled method for evaluating eddy current loss of ndfeb permanent magnets in a saturated core fault current limiter," IEEE Transactions on Magnetics, vol. 53, no. 6, 2017.

[14] M. Sun, R. Tang, X. Han, W. Tong, and J. Jia, "Analysis and calculation of zigzag leakage flux in surface mounted axial flux permanent magnet machines," Diangong Jishu Xuebao/Transactions of China Electrotechnical Society, vol. 32, no. 17, pp. 119-126, 2017.

[15] K. Dong, H. Yu, M. Hu, J. Liu, L. Huang, and J. Zhou, "Study of axial-flux-type superconducting eddy-current couplings," IEEE Transactions on Applied Superconductivity, vol. 27, no. 4, pp. 1-5, 2017.

[16] A. C. Barmpatza and J. C. Kappatou, "Finite element method investigation and loss estimation of a permanent magnet synchronous generator feeding a non-linear load," Energies, vol. 11, no. 12, p. 3404, 2018.

[17] P. Ying, R. Jiangjun, Z. Yu, and G. Yan, "A composite grid method for moving conductor eddy-current problem," IEEE Transactions on Magnetics, vol. 43, no. 7, pp. 3259-3265, 2007.

[18] F. Henrotte, H. Heumann, E. Lange, and K. Hameyer, "Upwind 3 -D vector potential formulation for electromagnetic braking simulations," IEEE Transactions on Magnetics, vol. 46, no. 8, pp. 2835-2838, 2010. 
[19] Y. Li, H. Lin, H. Yang, S. Fang, and H. Wang, "Analytical analysis of a novel flux adjustable permanent magnet eddycurrent coupling with a movable stator ring," IEEE Transactions on Magnetics, vol. 54, no. 3, 2018.

[20] Y. Li, H. Lin, H. Huang, H. Yang, Q. Tao, and S. Fang, "Analytical analysis of a novel brushless hybrid excited adjustable speed eddy current coupling," Energies, vol. 12, no. 2, p. 308, 2019.

[21] M.-F. Hsieh and Y.-C. Hsu, "A generalized magnetic circuit modeling approach for design of surface permanent-magnet machines," IEEE Transactions on Industrial Electronics, vol. 59, no. 2, pp. 779-792, 2012.

[22] W. Kemmetmuller, D. Faustner, and A. Kugi, "Modeling of a permanent magnet synchronous machine with internal magnets using magnetic equivalent circuits," IEEE Transactions on Magnetics, vol. 50, no. 6, 2014.

[23] B. Kou, Y. Jin, H. Zhang, L. Zhang, and H. Zhang, "Analysis and design of hybrid excitation linear eddy current brake," IEEE Transactions on Energy Conversion, vol. 29, no. 2, pp. 496-506, 2014.

[24] V. Aberoomand, M. Mirsalim, and R. Fesharakifard, "Design optimization of double-sided permanent-magnet axial eddycurrent couplers for use in dynamic applications," IEEE Transactions on Energy Conversion, pp. 1-1.

[25] S. Mohammadi and M. Mirsalim, "Design optimization of double-sided permanent-magnet radial-flux eddy-current couplers," Electric Power Systems Research, vol. 108, pp. 282-292, 2014.

[26] S. Mohammadi, M. Mirsalim, S. Vaez-Zadeh, and H. A. Talebi, "Analytical modeling and analysis of axial-flux interior permanent-magnet couplers," IEEE Transactions on Industrial Electronics, vol. 61, no. 11, pp. 5940-5947, 2014.

[27] S. Mohammadi, M. Mirsalim, and S. Vaez-Zadeh, "Nonlinear modeling of eddy-current couplers," IEEE Transactions on Energy Conversion, vol. 29, no. 1, pp. 224-231, 2014.

[28] J. Wang, H. Lin, S. Fang, and Y. Huang, "A general analytical model of permanent magnet eddy current couplings," IEEE Transactions on Magnetics, vol. 50, no. 1, pp. 1-9, 2014.

[29] J. Wang and J. Zhu, "A simple method for performance prediction of permanent magnet eddy current couplings using a new magnetic equivalent circuit model," IEEE Transactions on Industrial Electronics, vol. 65, no. 3, pp. 2487-2495, 2018.

[30] X. Dai, Q. Liang, J. Cao, Y. Long, J. Mo, and S. Wang, "Analytical modeling of axial-flux permanent magnet eddy current couplings with a slotted conductor topology," IEEE Transactions on Magnetics, vol. 52, no. 2, 2016.

[31] M. Merdzan, S. Jumayev, A. Borisavljevic, K. O. Boynov, J. J. Paulides, and E. Lomonova, "Electrical and magnetic model coupling of permanent magnet machines based on harmonic analysis," in Proceedings of the Magnetics Conference, IEEE, 2015.

[32] J. Wang, H. Lin, and S. Fang, "Analytical prediction of torque characteristics of eddy current couplings having a quasihalbach magnet structure," IEEE Transactions on Magnetics, vol. 52, no. 6, 2016.

[33] T. Lubin and A. Rezzoug, "Steady-state and transient performance of axial-field eddy-current coupling," IEEE Transactions on Industrial Electronics, vol. 62, no. 4, pp. 2287-2296, 2015.

[34] T. Lubin and A. Rezzoug, "3-D analytical model for axialflux eddy-current couplings and brakes under steady-state conditions," IEEE Transactions on Magnetics, vol. 51, no. 10, 2015.

[35] T. Lubin and A. Rezzoug, "Improved 3-D analytical model for axial-flux eddy-current couplings with curvature effects," IEEE Transactions on Magnetics, vol. 53, no. 9, 2017.
[36] D. Zheng, D. Wang, S. Li, T. Shi, Z. Li, and L. Yu, "Eddy current loss calculation and thermal analysis of axial-flux permanent magnet couplers," AIP Advances, vol. 7, no. 2, p. 025117, 2017.

[37] Z. Li, D. Wang, and D. Zheng, "Accurate prediction and analysis of electromagnetic fields and forces in Flux-Focusing eddy current coupling with double slotted conductor rotors," IEEE Access, vol. 6, pp. 37685-37699, 2018.

[38] D. Zheng, D. Wang, S. Li, H. Zhang, L. Yu, and Z. Li, "Electromagnetic-thermal model for improved axial-flux eddy current couplings with combine rectangle-shaped magnets," IEEE Access, vol. 6, pp. 26383-26390, 2018.

[39] A. Canova and B. Vusini, "Analytical modeling of rotating eddycurrent couplers," IEEE Transactions on Magnetics, vol. 41, no. 1 I, pp. 24-35, 2005.

[40] P.-D. Pfister and Y. Perriard, "Slotless permanent-magnet machines: General analytical magnetic field calculation," IEEE Transactions on Magnetics, vol. 47, no. 6, pp. 1739-1752, 2011.

[41] S. S. Mohan, M. D. M. Hershenson, S. P. Boyd, and T. H. Lee, "Simple accurate expressions for planar spiral inductances," IEEE Journal of Solid-State Circuits, vol. 34, no. 10, pp. 1419-1424, 1999.

[42] S. Jenei, B. K. J. C. Nauwelaers, and S. Decoutere, "Physics-based closed-form inductance expression for compact modeling of integrated spiral inductors," IEEE Journal of Solid-State Circuits, vol. 37, no. 1, pp. 77-80, 2002. 


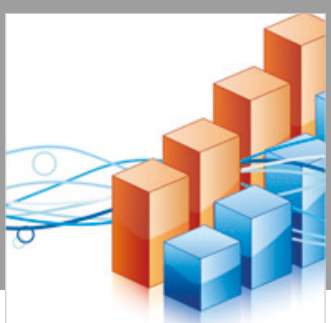

Advances in

Operations Research

\section{-n-m}
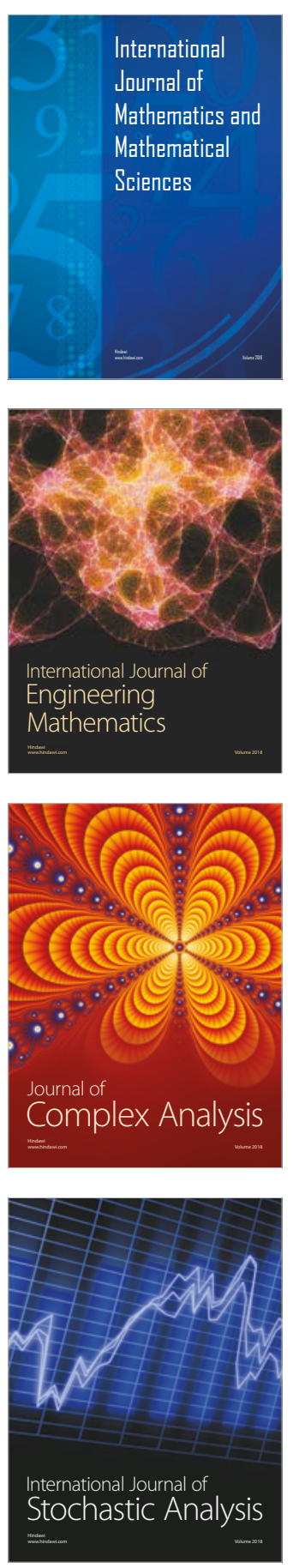
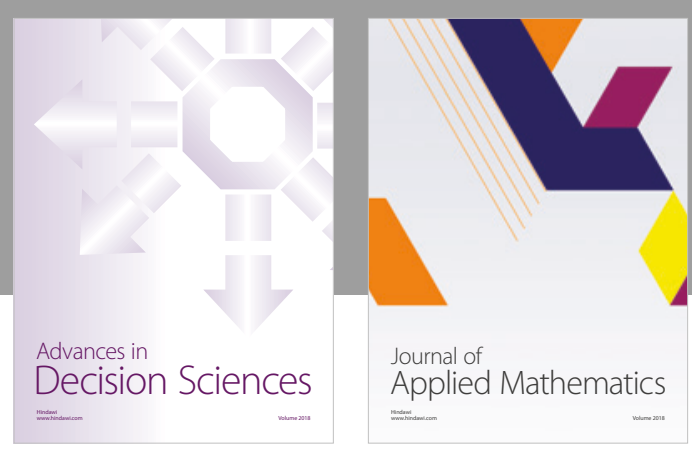

Journal of

Applied Mathematics
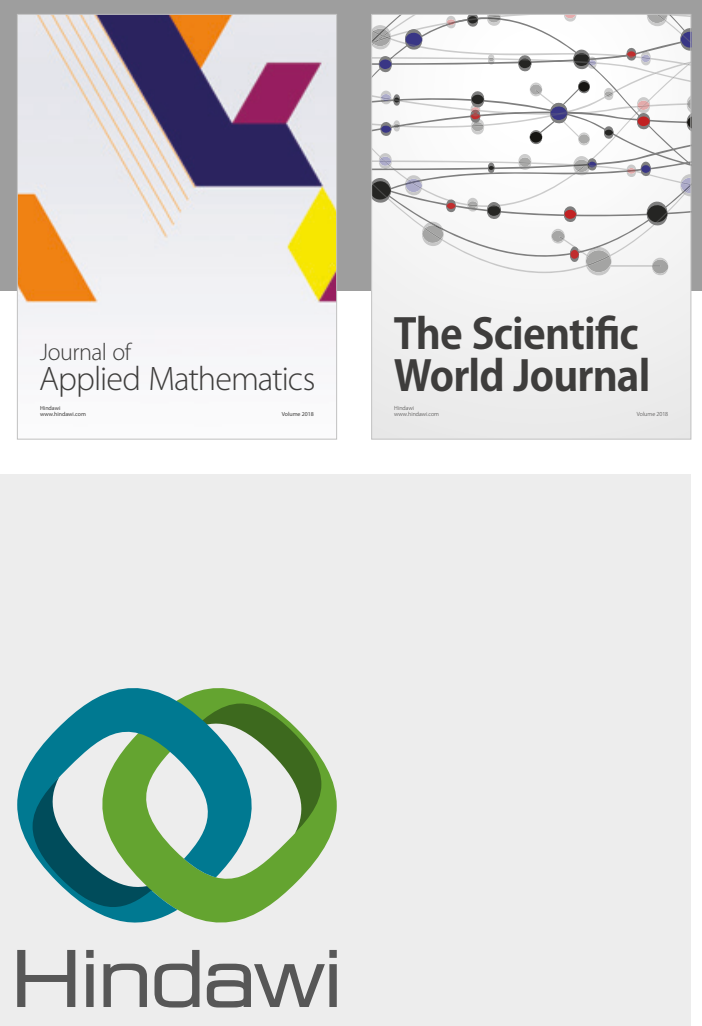

Submit your manuscripts at

www.hindawi.com

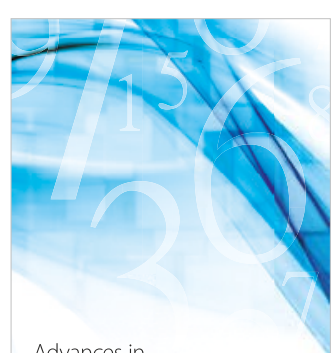

Advances in
Numerical Analysis
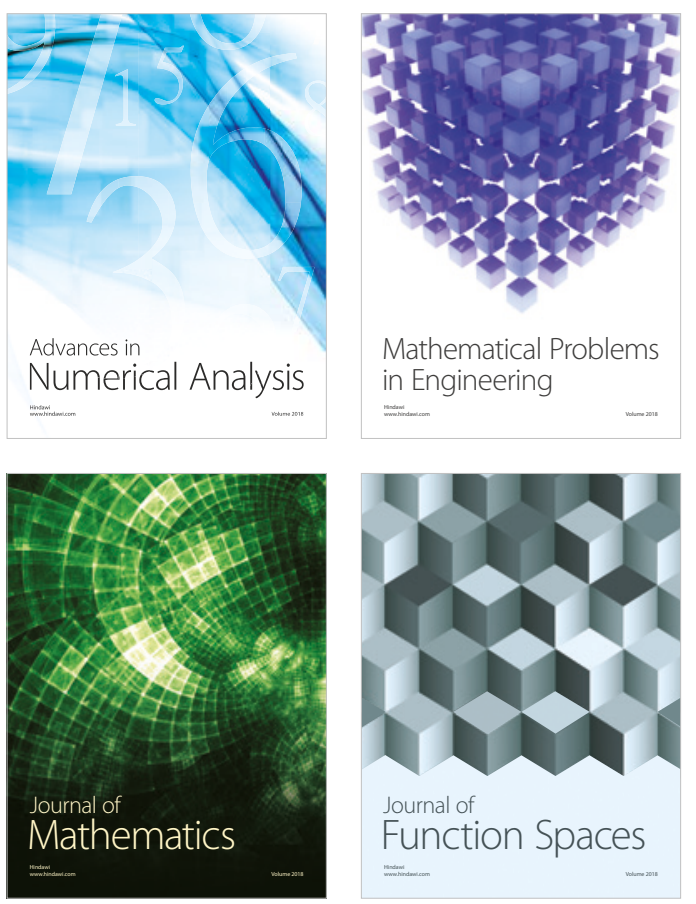

Mathematical Problems in Engineering

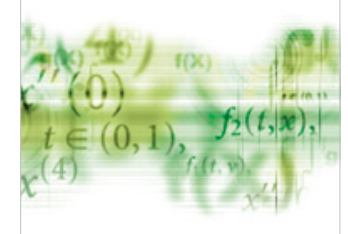

International Journal of

Differential Equations

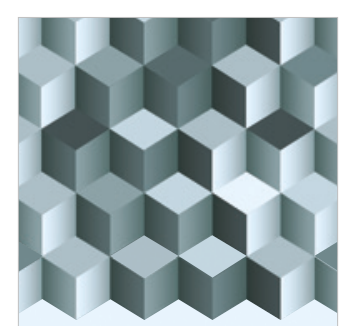

Journal of

Function Spaces

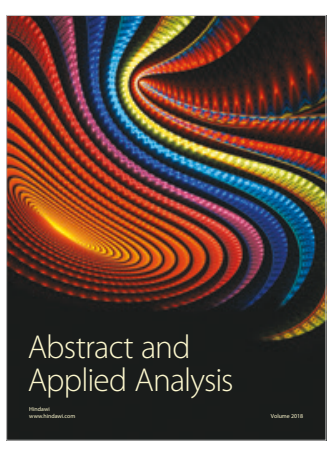

The Scientific

World Journal

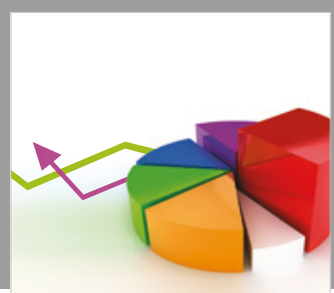

Journal of

Probability and Statistics
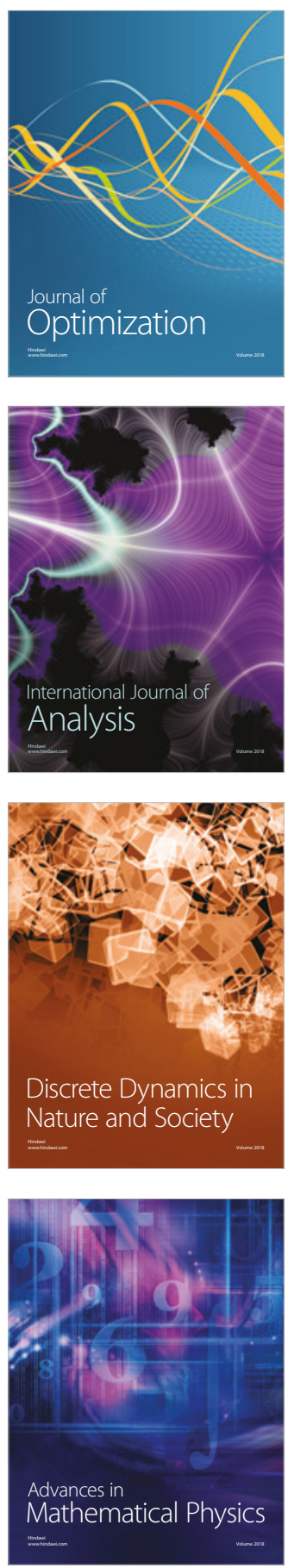